\title{
Blogging for Self-reflection among Pre-service English Language Teachers in Saudi Arabia: An Exploratory Study of Students' Own Reflections
}

\author{
Ahmed Al Khateeb \\ Department of English Language, King Faisal University, Al-Ahssa, Saudi Arabia \\ E-mail: Ahmed 9114@hotmail.com
}

Received: 28-04-2016

Published: 01-11-2016
Accepted: 04-07-2016

doi:10.7575/aiac.ijalel.v.5n.6p.1
Advance Access Published: September 2016

URL: http://dx.doi.org/10.7575/aiac.ijalel.v.5n.6p.1

\begin{abstract}
This study examines the involvement of blogging as a novel practice within a graduation project course for undergraduate students. The course involves writing a sound research proposal followed by accomplishing research in one of three main areas of study: linguistics, literature and translation. The participants consisted of fifty-five students learning E nglish as foreign language. They managed to create their own personal blogs, using Blogger, which were personal journals composed of their reflections and understanding of the process of writing a research paper in the form of multimodal literacy. The analysis of the data was qualitatively based through two means: an analysis of blog content and an open-survey for those who create such blogs. The survey includes questions such as whether the participants want to use blogging for other courses or not and why and what the merits and demerits of integrating blogs are with remaining courses. Through this practice, the students started to build on existing writing experience along with maximizing opportunities for autonomous thinking. This practice has also led the participants to consider writing research projects for advanced levels such as how to write a Masters dissertation.
\end{abstract}

Keywords: Blogging, Self-reflection, Writing, Teachers of English as a foreign language, a research paper

\section{Introduction}

First of all, blogging has been considered an integral part in order for the students to attain the utmost benefit of this course. Particularly, because it reinforces learners' ability to self-reflect on the content they learn, as well as supports their understanding of all the different elements that are necessary to write satisfactory research proposals. On the other hand, self-reflection in a critical and an analytical way is a life-long skill that benefits learners in the long term, as they need to apply it in order to develop their literacy and professional development as it mainly stresses learners' awareness. The process of blog-based self-reflection demands cognitive and neurological readiness due to its complexity and higher-thinking competence.

\section{Drivers of the study and the research question}

Little research has been conducted regarding the use of blogs for English language learning in general, whether as a second or foreign language, nor into its use for promoting self-reflection about the taught courses in contexts such as Saudi Arabia. Accordingly, the study intended to analyse whether the use of blogs would enhance students' proficiency and attitudes towards mastering the principles of writing and creating a successful research paper. It also aimed to give the participants a practical alternative which would impact their learning experience and consequently change their negative stereotype of the graduation project as a monotonous course. Therefore, the study intended to answer the following main research question:

- What are the impact and consequences of blogging for self-reflection on students' knowledge and their learning in terms of writing a successful research paper? (as part of their graduation project course)

\section{Theoretical grounding}

Blogging underlines constructivism and connectivism learning theories as they argue that content is a fundamental element required for people to gain wider knowledge. Constructivism learning theory posits learning as an experience and active process where learners should work as knowledge constructors. This view stem from Ben-Ari (1998) who asserted that learning knowledge is not passively absorbed from textbooks or lectures and comes as a result each learner constructing knowledge idiosyncratically. This learning theory also refers to peoples' ability to build a better understanding of the world through their experience of things and then their subsequent reflection on those things (ibid).

Connectivism is described as one of the theories of the twenty-first century, known as a learning theory for the digital age. Connectivism was suggested by Stephen Downes and George Siemens to describe the state of learning in the technological era that is swiftly evolving in the networked-based learning. This theory argues that the first step for learning to happen is "when knowledge is actuated through the process of a learner connecting to and feeding 
information into a learning community' (Kop and Hill, 2008). It proclaims learning to occur outside ourselves; within external resources such as certain databases or tools. It considers information and communication technology (ICT) as a pivotal supporter of gaining knowledge and enhancing cognition (ibid).

The connectivst model recognizes that learning is a complex, multifaceted and chaotic process which highly values the incorporation of up-to-date knowledge (Chatti, Jarke, Frosch-Wilke, 2007). Connectivists emphasize that learning is a product of the creative connection of aspects of knowledge (i.e. what, how and who) along with integrating existing networks (Siemens, 2006). It combines the 'principles explored by chaos, network, and complexity and selforganization theories' (Siemens, 2004). It is argued that connectivism is based on connecting different sets of information and sources; with the intent of increasing criticality in order to know the unknown. Siemens (2004) describes the stages of connectivism: from individual, to network, to organization. He states that 'personal knowledge is comprised of a network, which feeds into organizations and institutions, which in turn feed back into the network, and then continue to provide leaning to individual'.

In support of the theoretical and pedagogical benefits of such use of blogging, Farmer (2006) claims that blogging shows more dynamicity than many other online learning tools such as discussion forums, as it generates more focused communication of individuals which can be considered as part of a more responsible community in order to empower the process of learning. In addition, a learning community is considered as a node, which is part of a larger network that is composed of two or more nodes linked together in order to share resources.

\section{Reviewing the literature}

4.1 Blogs and blogging

A blog, or weblog, are described as

online journals where an author (or authors) publishes a series of chronological, updateable entries or posts on various topics, typically of personal interest to the author(s) and often expressed in a strongly subjective voice, on which readers are invited to comment (Farmer, Yue and Brooks, 2008).

The same researchers advocate that blogging regularly uses hypertextual facilities which involve linking different posts, providing links to other web content, and/or associating to other users' blogs. Blogs are websites which have entries appearing in reverse chronological order (latest entries are found at the top of the page) and can be authored by singular individuals as well as groups of users. A blog is one of the applications of the interactive web, what is called web 2.0, which should function as a platform for publishing personal information and assembling self-related anecdotes (Makri and Kynigos, 2007). Kaye (2006) emphasizes blogging as a medium of personal affirmation and idiosyncratic empowerment.

Blogosphere is a considered as a synonym of the concept 'public sphere', which is a space to exercise mutual communication and the expression of one's own individual voice (Barlow, 2007). Blogs can be accessed through two opposing, but at the same time complementing, practices: the individual and communal or, as Wrede (2003) describes it, 'monologue and dialogue', where users are able to express their own personal thoughts, and can be part of larger social networks of interactive contact and exchange.

Critical studies of blogging suggest that blogging 'has the potential to be a transformational technology for teaching and learning' (Williams and Jacobs, 2004) and being a form of computer-mediated communication (CMC). For instance, Farmer (2006) suggests that blogging would possibly contribute to higher-order (or meta-cognitive) thinking skills and learner-centered pedagogy. Generally speaking, blogging helps learners to foster life-long learning and its related skills in addition to spreading information, communication and reflection (Montero-Fleta and Pérez-Sabater, 2016). They also claim writing blogs benefits teachers and learners in terms of enhancing their professional practices due to the factors of interactivity and realism existing in blogs.

Blogging positively contributes to language learning and language skills, particularly writing, as it offers ample time for users to think about the public readers as has been reported by Pinkman (2005). Blogs promote self-expression for L2 learners to develop deeply personalised content dealing with their language learning strategies (Murray and Hourigan, 2008). Blogs have grown incredibly in the $21^{\text {st }}$ century and the number has exceeded more than seventy million weblogs globally (Sifry, 2007). A number of major advantages of blogging have been stated by Arena (2008) as

the choice of more appropriate language on the part of the learners, the addition of new perspectives to the learners' thoughts, and the motivational aspect of realizing that one's voice echoes in distant parts of the globe and is heard by others.

Kim (2008) determines the possible limitations relevant to computer-mediated communication (CMC) tools such as lack of archives, lack of posting, ownership, anxiety and instructor-centered system. On the contrary, as Kim (2008) confirms, it was claimed blogs help to overcome problems such as problems particularly because they comprise archives, decentralized system, more personal and rich site summary (RSS).

Besides its positive effects on reflection as mentioned earlier, Montero-Fleta and Pérez-Sabater and Pelletieri emphasize its panacea for improving weaknesses in grammar proficiency and fluency. In addition, Murray, Hourigan, and Jeanneau (2007) advocate working on blogs, as it produces web-oriented content that is accessible anywhere at any 
time, as well as drawing in new readers, whether they are classmates or anonymous, and their views. Blogs have specific areas for users to comment and respond to the blog post. Sun (2009) found that blogs are a helpful tactic for the development of authorship, learning strategies and motivation towards learning. It allows potential users to document their learning, and be self-centered, and share their mutual experience and knowledge.

Accordingly, different blogging systems have become supporters of formal and informal communication and community building (Divitini, Haugalokken, and Morken, 2005). Bogs can transcend linguistic barriers since bloggers: 'become part of a discourse community in a complex multimodal setting'. (Raith, 2009: 276). Such blog-oriented communities would provide useful informative supplementary materials for helping students' learning. Supporters of academic blogging consider it 'a reconceptualization of students as critical, collaborative, and creative participants in the social construction of knowledge' (Burgess, 2006, p. 105).

In short, the act of blogging refers to:

a. An application of social learning and social networking system.

b. A tool of the web 2.0 generation.

c. Using blogs for web-based/online diaries or personal journals.

d. Being compatible with other social software and tools

e. No requiring previous knowledge regarding HTML or Web scripting (easy interface).

f. A tool that can be read in different formats: rich site summary (RSS), tags, homepage, single post page and categories.

Yet, some studies showed that blogging did not augment learners' motivation due to the fact it lacks direct engagement (Divitini, Haugalokken, and Morken, 2005). Further shortcomings of blogging involve being a time consumer and distractor, requiring promotion and therefore there is a small likelihood of blog posts going viral.

\subsection{Reflection and self-reflective activities in language learning}

The term reflection is basically used to describe the returning of light from a smooth or watery surface. In this paper, reflection is not used in a literal sense, but rather to mean physical self-mirroring. Reflection refers to processing thoughts and feelings about an incident or event. Jasper (2003) defines it as 'the way that we learn from an experience in order to understand and develop practice'. Reflection is vital because it is part of the learning process which is based on connecting the schemata of the current experience with prior knowledge and it promotes learners' professional practice. Reflection is a sophisticated activity allowing participants to explore and explain instead of simply describing incidents or events.

In general terms, reflection is a thought-provoking activity due to it being more than just using a common sense or wisdom. The term reflection can be also practised differently despite sharing a number of characteristics such as being a mental process directed towards a purpose and an avenue for the representation of knowledge. Reid (1993) argues that 'reflection is a process of reviewing an experience of practice in order to describe, analyse, evaluate and so inform learning about experience' (p: 305).

Bengtsson (1995) describes two basic types of reflection: one's own activity which is based on cogitation and mediation regarding issues relevant to the individuals themselves. The other type is reflection on any other kind of objects other than one self, e.g. the contemplation of the universe. Bengtsson also shows that there is an additional type of reflection that sits in between these two types (i.e., between the other and the own) such as one's reflection on his/her professional practice.

Reflection upon one's own professional field includes, consequently, many things which are different than one's own professional activity and which reflection upon one's own professional practice will not uncover (p: 32).

Accordingly, the essence of reflection is thinking which must be preceded by self-discovery and self-attainment.

If thinking is preceded by self-discovery, then the second notion of reflection can complement the first notion of reflection, because if the first kind of reflection leads to self-discovery, it seems to be a natural continuation to dwell upon the discovered in order to understand it and gain knowledge about it (p: 33)

The primary goal of reflection and reflective practice is to support the thinking process and hence the construction of knowledge and meaning-making for the learner, as suggested by Ong (2000).

Self-reflection is an educational practice which involves people questioning themselves as to why they do something and then deciding whether there is a better way of doing it in the future. The Merriam-Webster dictionary describes self-reflection as careful thought about your own behaviours and beliefs. Self-reflection is a process of self-analysis, self-evaluation, self-dialogue, self-observation (Yip, 2006). Also, self-reflection is synonymous with other similar concepts such as: reflective practice, self-review and awareness, critical evaluation, self-appraisal and personal cognizance.

\section{The study}

\subsection{Information about graduation project}

The graduation project involves two basic milestones: the research proposal and final research paper. In order to achieve these steps, participants need to do the following: 
- Decide on accurate and researchable research questions

- Identify original/genuine topics

- $\quad$ Pinpoint the research gap(s)

- Consolidate theoretical bases with practice

- Develop methodological approaches

- Think about how to analyse their findings and their contributions to the research community

5.2 Setting and participants

The study took place in one of the public universities in Saudi Arabia and all the participants were female students who learned English as a foreign language. Since introducing English to the Saudi educational system, the students' academic achievement and their linguistic competence have not greatly progressed, due to a lack of exposure to the target language, and the reluctance to adopt recent technologies and social media tools in language classes along with the absence of a sound system for the examination and assessment of this subject.

The study participants, who had enrolled in the Graduation Project course, received the basic elements of making a research paper (e.g., how to formulate research questions, discover research gap, find appropriate literature and approach data analysis), as showed in the previous section over a sixteen-week course.

The participants were adult female students in their final semester of doing a bachelor in English language. This case study was comprised of students whose level ranged between B1 (threshold) and B2 (vantage). Those at B1 level have the capacity to describe familiar situations in a general way stating basic information. On the other hand, B2 includes students who have the ability to accomplish most goals and objectives and being able to express themselves on a range of common topics.

In terms of the students' digital competence, there was also a range of possibilities, with the majority being technology savvy, but with others who were less competent technologically.

\subsection{Methodology}

As part of the requirement of this course is to submit a successful research paper in line with the expected level of accuracy and fluidity, the four main criteria were emphasised to the participants at the beginning of the course: presentation of content, clarity of ideas, grammatical correctness and coherence and cohesion. The use and establishment of personal blogs were promoted as a mediating tool for empowering the participants' educational practices and linguistic production.

As far as the content and components of the blogs were concerned, the participants were given the opportunity to be as creative as possible by adding audio or video materials. The participants were also made aware of the significance of the quality of posts rather than just the quantity. The participants were given to special training which involved thinking about the key characteristic of self-reflection, that is to say, questioning. Gay and Kirkland (2003) confirm the following that:

Many preservice teachers simply repeat the trends, or the conventional reasons for why discrepancies exist, without examining their own personal positions on the issues, questioning traditional explanations, or analyzing how achievement dilemmas are influenced by culture, class, ethnicity, and racism (p: 183).

Accordingly, such reflective questions included:

- $\quad$ Skills (i.e., learnt skills)

- Problems (i.e., problems or challenges encountered)

- Weaknesses (i.e., discovered weaknesses)

- Achievements (i.e., experience achieved)

- Happiness (i.e., motivating factors)

- Strengths (i.e., things still to be remembered)

- Solutions (i.e., areas to be improved)

Regarding the research method used, the researcher used two main methods: content analysis of the participants' blogs and subsequent reporting the most frequent features. The other method used was a survey which primarily focused on an open-ended questionnaire. This reflective questionnaire contained questions such as:

- When you become an English language teacher will you be using blogs with your students as part of their education and why?

- Do you prefer blogging to be assessed or not to be assessed and why?

\section{Findings and data analysis}

\subsection{Samples from the participants' blogs}

As a sample for research purposes, four blogs were chosen randomly and analysed with a closer eye to determine the main components of each individual's blog, and it was found that the majority of blogs shared several characteristics such as using emoticons to represent their current mood. 


\section{Student A}

This student managed to take notes from different classes. She attempted to write what she has learnt in her voice and showing her reflection on these issues (e.g., main sections of writing a research paper) and how this experience changed her life. She designed her blog in an interesting way and used several images to help express her feelings.

\section{Student B}

This student was able to think about the positive impact of engaging in research and recognised the fact that it contributes to students' critical thinking and analytical skills. The student also managed to understand the importance of finding an appropriate theory and a theoretical framework before starting research. The produced blog provided additional personal perspectives and suggestions to support a cohesive and coherent understanding of the research elements.

\section{Student C}

This student worked hard to post regularly and deeply reflect on different elements taught in class (e.g., identifying the research niche). She thought blogs would complement what was already studied in the class. As was the case with many students, this student engaged more with expressive writing which enabled her to employ additional cognitive thoughts.

\section{Student D}

This student was able to achieve a good level of consciousness by transforming her thoughts into a written form. The voice of the student gradually improved, meaning that she started gaining self-confidence over time, as a result of social networking tool and its less-threatening environment.

\subsection{Open-ended questionnaires}

Generally speaking, the practice of establishing a personal blog supported the participants in terms of visualising and recording their ideas; creating skills for life-long learning and $21^{\text {st }}$ century learning and increased the ability to be part of a larger interactive and collaborative blog. Furthermore, the participants highlighted the helpfulness of blogging as it works for identifying their own linguistic needs, supporting writing (rhetorical) skills, and reducing the anxiety of making work available to the general public. Some expects provided by the participants will be shown below:

In relation to the question regarding if the students intend to use blogs in the near future when they become teachers. One student explained:

Yes, because it can be seen by others; which often motivates students to put forth their best work, and they will spend a little more time developing their ideas; they will make a conscious effort to impress others.

In response to the same question, one more participant supported the claim of the previous student by arguing the following:

I will absolutely use it in order to let the students interact with me and with each other. I believe that blogs encourage students to participate more and more because each student wants to stand out and wants his/her blog to be better than his/her colleagues. In response, it creates a sort of competition between students. Also, it keeps the instructor aware of his/her student's progress.

Another participant expressed an opposite perspective believing that there are alternative tools which are more easily accessed by students.

Probably not, because it's an old way, especially in Saudi Arabia. It's rare to see someone using it. So if I did that I would see a lack of effort and complaining from the students about it. So I'd rather use something more common and easier to deal with, like maybe facebook, twitter, whatsapp and any other social media.

As far as the question about advantages and disadvantages of using blogs as part of the course requirement is concerned, one student commented on the positive side of dealing with such as interactive tool:

It is positive in terms of changing the traditional teaching methods. Another positive point is that these blogs can actually enhance student's abilities to think out of the box. For me, I didn't experience any disadvantages at all.

The same student also continued to mention the benefits of using blogs on an individual level.

... the blog was really beneficial for me. It helped me in documenting the information that I have learned during the lectures. I also found it an interesting tool to improve my writing skills. Blogs can also encourage students to share useful information with others.

Furthermore, one of the participants stated more advantages regarding the use of blogs in traditional learning for more self-reflection.

... blogging in my opinion is better than writing our ideas on paper because I know that my blog will be read by many others since it's on the internet. Also, blogging can offer opportunities for students to develop their communication skills. Furthermore, blogging projects not only motivate students to write, but motivate them to write well.

Another student also went on to explain other merits, as well as demerits of integrating blogs in language learning classes from a different perspective. She declared the following: 
... maybe one of the advantages is the individuality, as a teacher I want to be aware of the students full ability to express themselves and if they have any issue with my teaching methods, at the end blogs are free spaces for your own ideas, opinions, words and for any suggestions. On the other hand, the disadvantage is there is no teamwork.

The participants were asked about whether it is preferable for blogs to be assessed or not, or whether it should be entirely optional. The majority liked the idea of assessing blogs by assigning a few marks for the accomplishment of this task. Here are some of these views which were conveyed by different participants:

I think that blog must be assessed to know if the use of blogs was efficient or not on the learning process.

I prefer blogging to be assessed. That will help students to correct their mistakes and improve their writing and communication skills at the same time.

My blog helped me to summarise all I have learnt from the lectures ... it helped me to create good notes that are always available online.

Well, if there will be no marks involved, there will be less pressure on the students. However, I prefer the first choice; because the students will put more effort into their blogs if they are going to be assessed.

One of the participants drew attention to the time factor, emphasising the importance of creating blogs that are based on self-reflection from the beginning of the semester.

... I mean ask them to write what they learn in each lecture one by one because in the previous semester we've created our blogs in the middle of the semester, so we did not have enough time to write all that we did learn in each class.

In relation to the future ideas suggested by the participants, one participant recommended the use of an immense blog (for the entire students in the class), besides the individual blogs, in order to alter the existing environment, which is based on sharing, motivation and collaboration.

I would rather the students to share one blog, instead of having one blog for each student to make them interact with one another. This idea will also make it easier for the instructor to take a look at the students' posts and comment on them easily.

\section{Discussion, conclusions and future research}

This research discovered that students should be encouraged to develop their skills through the selection and use of blogs, as well as perhaps any other social networking tool, which would highlight personal-oriented learning. In fact, digital (or blog-based) reading and writing have become among the most fundamental sources of language learning practice that the new generation of students are required to be familiar with, particularly in the information, communication and technology age, what is known as digital literacy. This finding agrees with what was proposed by Phillips (2016) regarding the role of digital technology in the current time.

The inherent social aspect of both asynchronous online learning tools (e.g. blogs, discussion forums, glossaries, wikis) and synchronous tools (e.g. instant messaging, chat rooms, social media networking sites) affords numerous opportunities for a high level of communicative interaction outside the classroom.

That is because such involvement online engages users to read and write easily and by using additional functions such as audio or video multimedia. Consequently, digital reading and writing, as provided by blogs, provides the opportunity for better self-reflection, as learners can easily post written texts on the writing process, details of the research project and commentaries on lessons that have been recently studied.

It was also found that it is important to properly invest in technology for classrooms, as it contributes to a welcome change in the routine and creates a new environment for learning where instructors can work as moderators or facilitators, rather than being the only source of knowledge. This supports the findings of a number of researchers who found that recently used educational social tools such as blogs mediate knowledge management and cognitive construction (Minocha and Kerawalla, 2011). Using more technology would lead to several benefits including students' constructing their own identities, without any embarrassment of sharing online and to the public. It would enable users to work socially in learning communities where can be more easily achieved through cyberspace without time or space limitation. What is more, users are expected to be more willing to accept others and their differences when they become part of a wider learning community.

Based on analysis of the content of the blogs produced by the participants and the comments given by the students regarding the incorporation of blogging in this course, it was found that blogs enhance self-confidence and interactivity and social interaction, which are all believed to be effective as long as they are connected to the course material, as suggested by Dabbagh and Kitsantas (2011). The current results also showed evidence that blogging would trigger an increase in supporting skills for learning to manifest such as motivation, commitment and planning and organizational abilities. It is believed that such skills are pivotal for increasing individuals' ability to navigate learning environments in terms of improving self-regulation, self-awareness and familiarity with content.

Another advantage of using blogs in teaching for self-reflection and language learning skills was that they were found to create a better connection among students. This connection took place when a student posted a text on a blog which was followed by a comment from one of her peers providing supportive feedback and additional suggestions. As a 
result, blogging helps students to keep in touch with the rest of their classmates as a real audience and to achieve more communication that is grounded in peer feedback given either on online or in a face-to-face setting.

Based on the discussion given above, this research has reached a number of recommendations regarding the act of blogging for self-reflection on language learning for research projects as follows:

a. Blogs should be used as part of other courses.

b. They should be introduced at the beginning of the term.

c. They should be promoted by instructors and institutions.

d. They can be used in higher and public education.

e. They can be used for the self-reflection of any course, rather than just research projects.

f. They should be assessed by allocating minimal grades.

The current research investigated the influence of blogs on reinforcing self-reflective practice, as part of their language learning process. It was found that writing skills and strategies have been dramatically transformed due to the invention of social technologies; blogs are just one such tool. Future research will examine the use of developing a global, rather than an individual, blog where each student will be enabled to participate as part of community of practice and a team for collaborative language learning in a social setting. A new group of students, who are enrolled on a different course, will be given different tasks to encourage their self-reflective practices in relation to language learning, with necessary amendments being made in order to make the tasks more suitable for group work. The purpose of this comparison will allow the researcher to compare the learning outcomes between individual and collaborative blogs.

\section{References}

Arena, C. (2008), Blogging in the language classroom: It doesn't simply happen, TSEL-EJ. Teaching English as a Second or Foreign Language, 1(4), 1-7.

Barlow, A. (2007). The Rise of the Blogosphere. Westport, Connecticut: Praeger.

Ben-Ari, M., (1998), Constructivism in computer science education. In Acm sigcse bulletin, 30(1), $257-261$.

Bengtsson, J. (1995). What is reflection? On reflection in the teaching profession and teacher education. Teachers and Teaching: theory and practice, 1(1), 23-32.

Burgess, J. (2006). Blogging to learn, learning to blog. In A. Bruns and J. Jacobs (Eds.), Uses of blogs (105-114). New York: Peter Lang.

Chatti, M.A., Jarke, M. and Frosch-Wilke, D. (2007). The future of e-learning: a shift to knowledge networking and social software. International Journal of Knowledge and Learning, 3(4-5), 404-420.

Kitsantas, A. and Dabbagh, N. (2011). The role of Web 2.0 technologies in self-regulated learning. New Directions for Teaching and Learning, (126), 99-106.

Divitini, M., Haugalokken, O. and Morken, E. M. (2005). Blog to support learning in the field: Lessons learned from a fiasco. In Proceedings of the Fifth IEEE International Conference on Advanced Learning Technologies (ICALT'05).

Farmer, J. (2006). Blogging to basics: How blogs are bringing online education back from the brink. In A. Bruns and J. Jacobs (Eds.), Uses of Blogs (91-103). New York: Peter Lang.

Farmer, B., Yue, A. and Brooks, C. (2008). Using blogging for higher order learning in large cohort university teaching: A case study. Australasian Journal of Educational Technology, 24(2), 123-136.

Gay, G. and Kirkland, K. (2003). Developing cultural critical consciousness and self-reflection in preservice teacher education. Theory Into Practice, 42(3), 181-187.

Jasper, M. (2003). Beginning Reflective Practice. London: Nelson Thornes.

Makri, K. and Kynigos, C. (2007). The Role of Blogs in Studying the Discourse and Social Practices of Mathematics Teachers. Educational Technology and Society, 10(1), 73-84.

Kaye, B. K. (2006). Blog use motivations: An exploratory study. In M. Tremayne (Ed.), Blogging, Citizenship, and the Future of Media. New York: Routledge.

Kim, H. N. (2008). The phenomenon of blogs and theoretical model of blog use in educational context. Computers and Education, 52,1342-1352.

Kop, R. and Hill, A. (2008). Connectivism: Learning theory of the future or vestige of the past? The International Review of Research in Open and Distributed Learning, 9(3).

Minocha, S. and Kerawalla, L. (2011). University students' self-motivated blogging and development of study skills and research skills. In M. J. W. Lee and C. McLoughlin (Eds.), Web 2.0-based e-Learning: Applying social informatics for tertiary teaching (149-179). Hershey, PA: IGI Global.

Montero-Fleta, B. and Pérez-Sabater, C., 2016. Communicating Virtually: The Case of Blogging in Professional Environments. International Journal of Information and Education Technology, 6(7), 534-537.

Montero-Fleta B. and Pérez-Sabater, C. (2010), A research on blogging as a platform to enhance language skills, Procedia - Social and Behavioral Sciences, 2(2), 773-777.

Murray, L. and Hourigan, T. (2008). Blogs for specific purposes: Expressivist or socio-cogntivist approach? ReCALL, 20(1), 82-97.

Murray, L., Hourigan, T. and Jeanneau, C. (2007). Blog writing integration for academic language learning purposes: Towards an assessment framework. Ibérica: Revista de la Asociación Europea de Lenguas para Fines Especificos (AELFE), (14), 9-32. 
Ong, R. (2000). The Role of Reflection in Student Learning: A Study of its Effectiveness in Complementing Problembased Learning Environments. Centre for Educational Development.

Pellettieri, J. (2000), Negotiation in cyberspace: The role of chatting in the development of grammatical competence, in M. Warschauer and R. Kern, eds., Network-Based Language Teaching: Concepts and Practice, New York: Cambridge University Press, 59-86.

Philips, B (2016). Beyond Classroom Learning: Personalized Learning Through Digital Technologies http://webcache.googleusercontent.com/search?q=cache:wcrhlQ_RbyIJ:ffhoarep.fhooe.at/bitstream/123456789/664/1/1 20_214_Phillips_FullPaper_en_Final.pdf $+\& \mathrm{~cd}=1 \& \mathrm{hl}=\mathrm{en} \& \mathrm{ct}=\mathrm{clnk}$ (Accessed 10 $0^{\text {th }}$ August 2015).

Pinkman, K. (2005), Using blogs in the foreign language classroom, The JALT Call Journal, 1(1), 12-24.

Reid B (1993) 'But We're Doing it Already!' Exploring a Response to the Concept of Reflective Practice in Order to Improve its Facilitation, Nurse Education Today, 13, 305-309.

Siemens, G. (2004). Connectivism. A Learning Theory for the Digital Age. In eLearnSpace, http://www.elearnspace.org/Articles/connectivism.htm (Accessed 3rd January 2016).

Siemens, G. (2006). Connectivism: Learning Theory or Pastime of the Self-Amused? Manitoba, Canada: Learning Technologies Centre, http://www.elearnspace.org/Articles/connectivism_self-amused.htm (Accessed 15th March, 2016).

Sifry, D. (2007). The state of the live web, April 2007. Technorati Blog, http://technorati.com/weblog/2007/04/328.html (Accessed $2^{\text {nd }}$ February 2016).

Sun, Y. (2009), Voice blog: An exploratory study of language learning, Language Learning and Technology, 13(2), 88103.

Tremayne, M. (2006). Blogging, Citizenship and the Future of Media. New York: Routledge.

Walinski, J. (2005). Monitoring e-learners' feedback with blogs. Corpora and ICT in Language Studies. Proceedings of PALC, 431- 443.

Williams, J. B. and Jacobs, J. S. (2004). Exploring the use of blogs as learning spaces in the higher education sector. Australasian Journal of Educational Technology, 20(2), 232-247.

Wrede, O. (2003). Weblogs and Discourse: Weblogs as a transformational technology for higher education and academic research, Blogtalk Conference Paper, Vienna, May 23rd-24th 2003. Available online: http://weblogs.design.fh-aachen.de/owrede/publikationen/weblogs_and_discourse (Accessed 20 March 2016).

Yip, K.S., 2006. Self-reflection in reflective practice: A note of caution. British Journal of Social Work, 36(5), 777-788. 